\title{
Effects of Ganoderma Lucidum Extract on Morphine- Induced Addiction and Memory Impairment in Mice
}

\author{
Yen Hoang Tran ${ }^{1 \mathbb{D}}$, Tram Thi Thu Nguyen ${ }^{2, *} \mathbb{D}$, Phuong Thi Nguyen ${ }^{1 \mathbb{D}}$, Kien Trung Nguyen ${ }^{3} \mathbb{D}$, Chu \\ Xuan Duong 1(D), Hung Manh Tran ${ }^{4, *(\mathbb{D})}$
}

1 Department of Pharmacology and Clinical Pharmacy, Faculty of Pharmacy, Can Tho University of Medicine and Pharmacy, 179 Nguyen Van Cu, Can Tho 94000, Vietnam; thyen@ctump.edu.vn (Y.H.T.); phuongnguyen5658@gmail.com (P.T.N.); dxchu@ ctump.edu.vn (C.X.D.);

2 Department of Chemistry, Faculty of Sciences, Can Tho University of Medicine and Pharmacy, 179 Nguyen Van Cu, Can Tho 94000, Vietnam; ntttram@ctump.edu.vn (T.T.T.N.);

3 Department of Physiology, Faculty of Medicine, Can Tho University of Medicine and Pharmacy, 179 Nguyen Van $\mathrm{Cu}$, Can Tho 94000, Vietnam; ntkien@ctump.edu.vn (K.T.N.);

4 Department of Pharmacology, Faculty of Pharmacy, University of Medicine and Pharmacy at Ho Chi Minh City, 41 Dinh Tien Hoang, Ho Chi Minh City 71006, Vietnam; manhhung@ump.edu.vn (H.M.T.);

* Correspondence: ntttram@ctump.edu.vn (T.T.T.N.); manhhung@ump.edu.vn (H.M.T.);

Scopus Authors ID 57209166194 (T.T.T.N.) 57209885477 (H.M.T.)

Received: 15.03.2021; Revised: 15.04.2021; Accepted: 18.04.2021; Published: 26.04.2021

\begin{abstract}
Ganoderma lucidum extract (Lingzhi) has been used so far with various pharmacological effects. However, the reports on its effects on drug addiction, especially morphine, and morphineinduced memory impairment in vivo, remain limited. In the present study, the effect of G. lucidum extracts on preventing morphine addiction was evaluated by the conditioned place preference model. The extract's learning and memory improvement activities on morphine-induced memory loss were examined using Y maze, novel recognition, and Morris water maze tests. The results found that $G$. lucidum extracts at doses of 200-400 mg/kg decreased conditioned place preference score and increased the percentage of alteration, novel object exploration, and prolongation of locating hidden platform. With these doses, G. lucidum extracts prevented morphine addiction and improved short-term memory, visual memory, and long-term memory impairment caused by morphine. Our results first demonstrated that G. lucidum extracts promised as an effective natural source in treating drug addiction and morphine-induced memory loss.
\end{abstract}

Keywords: conditioned place preference; Ganoderma lucidum; morphine; object recognition memory; spatial memory.

(C) 2021 by the authors. This article is an open-access article distributed under the terms and conditions of the Creative Commons Attribution (CC BY) license (https://creativecommons.org/licenses/by/4.0/).

\section{Introduction}

Drug addiction has become a vital problem in many countries in the world [1]. In 2018, approximately 269 million people used drugs worldwide, and opioids were well-documented to be the most detrimental agents resulting in drug-related disorders and deaths over the past 2010s [2]. Morphine, one of the most effective opioid analgesics, which is clinically used to treat acute and chronic pain, will lead to addiction as repeated use. For the maintenance of analgesia, a higher dose of morphine is often required, increasing certain adverse effects such as withdrawal symptoms, respiratory depression, and rewarding effects with a high risk of relapse [3, 4]. The long-term use of morphine may cause memory loss, depression, and concentration loss [4-8]. Recently, natural extracts have received wide attention in finding new 
agents for the treatment of drug addiction [9-11]. Many traditional medicinal plants have been used, such as Portulaca oleraceae to reduce morphine dependence, Sophora alopecuroides alleviated morphine withdrawal syndrome, and Pimpinella anisum decreased morphine tolerance and physical dependence [12-14]. In Vietnam, Ganoderma lucidum (Leyss ex. Fr.) Karst. has been considered a precious herbal medicine due to its various pharmacological properties such as neurasthenia treatment, hepatoprotection, antioxidant and anticancer activities, and immune system boost [15-18]. Moreover, previous studies also showed that $G$. lucidum extract (GL) can prevent $\beta$-amyloid-induced memory impairment in mice or streptozocin-induced memory damage in rats by conditioned place preference paradigm [19, 20]. Since prolonged use of morphine has side effects on the central nervous system and a little information on the effects of GL on morphine addiction has been published, this research investigates the effects of GL on morphine-induced addiction and memory impairment in animal models.

\section{Materials and Methods}

\subsection{Animal.}

Healthy male Swiss albino mice, weighing about 20 - $25 \mathrm{~g}$ body weight, were purchased from Pasteur Institute in Ho Chi Minh City, Vietnam. The mice were housed and maintained under alternating light and dark cycles of 12 hours each (between 7:00 AM. to 7:00 PM) for 7 days before conducting experiments, water, and food ad libitum. All behavioral experiments were conducted at a light level of $100 \pm 5$ lux, the temperature of $27 \pm 1^{\circ} \mathrm{C}$, and limited noise. Handling of the animals was performed according to the instruction of lab-used and cared animals [21].

\subsection{Extract and drugs.}

The aqueous extract of G. lucidum was provided by OPC Pharmaceutical Joint Stock Co., Vietnam (Batch No.170007). Morphine $\mathrm{HCl}$, naloxone $\mathrm{HCl}$, and galantamine were obtained from Vidipha Pharmaceutical Joint Stock Co., Rotexmedica, and Janssen Cilag.

\subsection{Equipments.}

Conditioned place preference paradigm simulated Bardo and fellows' model (2000) [22]. Y maze paradigm simulated Kitanaka and fellows' model (2015) [23]. Novel recognition paradigm simulated Bertaina-Anglade and fellows' model (2006) [24]. Morris water maze paradigm simulated Rudi and fellows' model (2001) [25].

\subsection{Effect of GL on morphine addiction.}

Mice were randomly divided into five groups (8-10 mice/group), as follows group 1: vehicle control group (distilled water - ED); group 2: morphine $10 \mathrm{mg} / \mathrm{kg}$, IP; group 3: GL $200 \mathrm{mg} / \mathrm{kg}$, PO and morphine $10 \mathrm{mg} / \mathrm{kg}$, IP; group 4: GL $400 \mathrm{mg} / \mathrm{kg}, \mathrm{PO}$ and morphine 10 $\mathrm{mg} / \mathrm{kg}$, IP; and group 5: naltrexone $10 \mathrm{mg} / \mathrm{kg}$, PO and morphine $10 \mathrm{mg} / \mathrm{kg}$, IP. The experiment consisted of three phases. For the pre-conditioning phase, on day 1, mice were placed into the apparatus and left to discover the experimental environment for 15 minutes; on day 2, a conditioned place preference test (CPP) was conducted for 15 minutes, and the amount of time the mice remained in each compartment was recorded. For the conditioning phase, mice were 
administered ED or GL or naltrexone in 14 consecutive days. On days 1, 3, 5, 7, 9, 11, and 13, mice were orally taken ED or GL or naltrexone one hour before being injected $\mathrm{NaCl} 0.9 \%$ or morphine and then confined in the white compartment within 30 minutes. On days 2, 4, 6, 8, 10,12 , and 14, mice were orally taken $\mathrm{ED}$ one hour before being injected $\mathrm{NaCl} 0.9 \%$, then confined in the black compartment within 30 minutes. On day 14 , mice were received $\mathrm{NaCl}$ $0.9 \%$ one hour prior to conducting the CPP test within 15 minutes for the post-conditioning phase. The time that the experimental mice remained in each compartment was recorded. CPP value was established by differences in the amount of time mice remained in the white compartment before and after being conditioned [7, 8, 22]. GL was considered effective as CPP scores of GL group were significantly lower than those of the morphine group.

\subsection{Effect of GL on morphine-induced memory impairment.}

Mice were separated into five groups (8-10 mice/group) at random, as the experiment 2.4 above. Mice were injected $\mathrm{NaCl} 0.9 \%$ or morphine $10 \mathrm{mg} / \mathrm{kg}$ one hour after being orally administered ED, GL $200 \mathrm{mg} / \mathrm{kg}$, GL $400 \mathrm{mg} / \mathrm{kg}$, or galantamine $10 \mathrm{mg} / \mathrm{kg}$. Dosage regimens were repeated every 2 days in 14 days. The following experiments were conducted 24 hours after the last $\mathrm{NaCl} 0.9 \%$ and morphine injection.

\subsubsection{Y maze test.}

The mice were placed into the maze center and allowed to explore three arms within 8 minutes. Each arm of the maze was labeled as either arm A, B, or C. The entry was considered when all four limbs were within the arm. The number of arm entries and several alternations were scored to calculate the alternation percentage [23].

\subsubsection{Novel object recognition test.}

The task procedure consisted of three phases, including the habituation phase (the mice were individually placed into the box and allowed to explore the experimental environment for 8 minutes freely), the training phase (the mice were individually placed back into the box containing the presence of two different objects for 10 minutes. The amount of time the mice spent in exploring each of the objects in the training phase was recorded in order to find the preference object to be continued using in the test phase) and test phase (the mice were turned back to the box containing two objects, one familiar object used in the training phase and one novel object. The amount of time the mice spent exploring each of the objects was recorded. The test phase was carried out 24 hours after the training phase). The Preference Index was used to assess the mice's ability to memorize and distinguish either familiar or novel objects $[23,24]$.

\subsubsection{Morris water maze test.}

The mice underwent three consecutive tests within 8 days [23, 25]. Hidden platform test (the first 4 days): a hidden platform was placed approximately $2 \mathrm{~cm}$ beneath the water surface. The mice were individually given 5 trials per day for 4 consecutive days. On the first trial of day 1, when the mice did not find the platform within 60 seconds, they were guided to the platform and kept standing in there for 15 seconds. In the remaining trials, the mice were placed in various positions and were not provided guides. They had to locate the hidden platform within 60 seconds. The mice's amount of time to locate the hidden platform was 
recorded (the escape latency). Probe test (day 5): the hidden platform was placed approximately $10 \mathrm{~cm}$ beneath the water surface. Each trial took 60 seconds. The number of times that the mice swam across the former hidden platform area was recorded. Action memory test (days 6, 7, 8): five trials would be carried out per day, and it took 60 seconds for each trial. The hidden platform position was changed every day. The amount of time the mice took to locate the hidden platform was recorded.

\subsection{Statistical analysis.}

Data were presented as mean values \pm the standard error of the mean (S.E.M.). The data was analyzed by Minitab 14.0 software. The data series were compared by the Kruskal-Wallis test. In cases of differences, pairs of the number were analyzed by the Mann-Whitney test. A $p$-value equal to or less than 0.05 represents the statistical significance of change $(p<0.05)$. The graphs were drawn by Microsoft Excel 2016.

\section{Results and Discussion}

\subsection{Effect of GL on morphine addiction.}

Figure 1 showed that the CPP scores of experimental groups were significantly higher than those of the control group ( $p<0.05 v s$ morphine group, $p<0.01 v s$ all the remaining groups). A significant reduction in the amount of time was observed in the mice groups treated with GL spent in the white compartment compared to the mice in the control group. It suggested that GL reduced notably morphine addiction severity. In comparison, morphine addiction severeness was nearly disappeared in the group of mice treated with naltrexone.

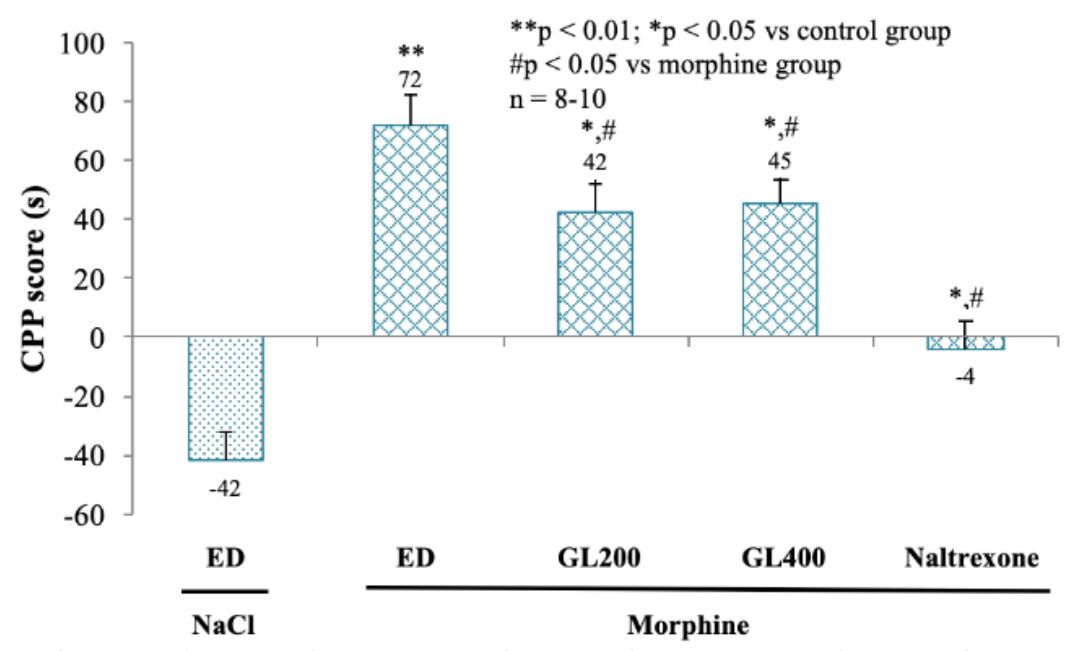

Figure 1. CPP scores of experimental groups.

The CPP paradigm is the standard preclinical experiment, which is commonly used to measure a stimulus's preference associated with a rewarding effect as drugs or food. It plays an important role in studying drug addiction-related dilemmas, mechanisms, and addictive potential of some substances, including morphine [26-28]. Normally, mice tend to reduce movements and spend almost time remaining in dark places when being familiar with the environment, which was clearly proved by a decrease of time in moving to the white compartment and an increase of time in remaining in the black one of the control group [8, 22]. However, when mice were treated with multiple repetitions of morphine in the white 
compartment, a significant change was recorded in mice's behavior that they were increasingly keen on being in the white compartment than before. The naltrexone group's results demonstrated that a co-administration of naltrexone and morphine in the conditioning phase considerably reduced the time remained in the white compartment of the mice and the morphine-induced CPP score. As a morphine antagonist, naltrexone would compete for morphine at opioid receptors when co-administered with morphine, thereby reversing the psychological dependence on morphine. In this study, the experimental data presented that the CPP scores in the groups administered GL was significantly lower than the morphine group. It proved the effects of GL on reducing the time mice remaining in the white compartment, compared with the mice treated with morphine. The results suggested the presence of bioactive compounds in GL producing antagonistic effects on opioid receptors, leading to the reduction of morphine addictive effects. It first showed a potential new treatment therapy for morphine withdrawal by adding GL to the current traditional herbal medicine composition.

\subsection{Effect of GL on morphine-induced memory impairment.}

Based on the survey of doses [29], morphine $10 \mathrm{mg} / \mathrm{kg}$, IP was used to investigate memory improvement of GL.

\subsubsection{Y maze test.}

The results of Y maze test in all groups were presented in Table 1. In Y maze test, no significant difference was observed in the number of arm entries among groups of morphine, GL $200 \mathrm{mg} / \mathrm{kg}$, GL $400 \mathrm{mg} / \mathrm{kg}$, and galantamine compared to the control group ( $\mathrm{NaCl} 0.9 \%$ ). However, the alternation percentage recorded a significant decrease $(p<0.05)$ compared to the control group, proving the morphine effect on short-term spatial memory impairment. Galantamine had positive effects on almost entirely recovering morphine-induced spatial memory impairment. GL at doses of $200 \mathrm{mg} / \mathrm{kg}$ and $400 \mathrm{mg} / \mathrm{kg}$ demonstrated a partial improvement in morphine-induced spatial memory deterioration $(p<0.05)$.

Table 1. Number of arm entries and the alternation percentage in groups.

\begin{tabular}{l|c|c} 
Group & Number of arm entries & Alternation percentage \\
\hline $\mathrm{NaCl} \mathrm{0.9 \%}(\mathrm{n}=8)$ & $30.00 \pm 2.38$ & $79.59 \pm 6.38$ \\
\hline Morphine $(\mathrm{n}=10)$ & $34.10 \pm 2.74$ & $55.37 \pm 4.47^{*}$ \\
\hline GL200 + Morphine $(\mathrm{n}=10)$ & $30.14 \pm 2.06$ & $67.11 \pm 5.22^{\#}$ \\
\hline GL400 + Morphine $(\mathrm{n}=10)$ & $31.33 \pm 1.66$ & $61.23 \pm 6.76^{\#}$ \\
\hline Galantamine + Morphine $(\mathrm{n}=10)$ & $31.00 \pm 2.43$ & $69.42 \pm 8.13^{\# \#}$ \\
$* \mathrm{p}<0.05$ compared to $\mathrm{NaCl} \mathrm{0.9 \%} \mathrm{group;} \# \mathrm{p}<0.05 ; \# \# \mathrm{p}<0.01$ compared to morphine group
\end{tabular}

\subsubsection{Novel object recognition test.}

The results illustrated the preference indexes of object $A$ in all groups higher than those of object B $(p<0.05)$; hence object A was used as the familiar item for the next experiment (Figure 2). At the stage of testing, the groups of mice received GL at doses of $200 \mathrm{mg} / \mathrm{kg}$, and $400 \mathrm{mg} / \mathrm{kg}$ recorded notable increases in the preference indexes of object $\mathrm{C}$ compared to those of object A $(p<0.01)$, and no significant difference compared to galantamine $(p>0.05)$ (Figure $3)$. In comparison, the morphine group recorded the reverse results. Those results proved the effects of GL on improving morphine-induced visual memory impairment. 


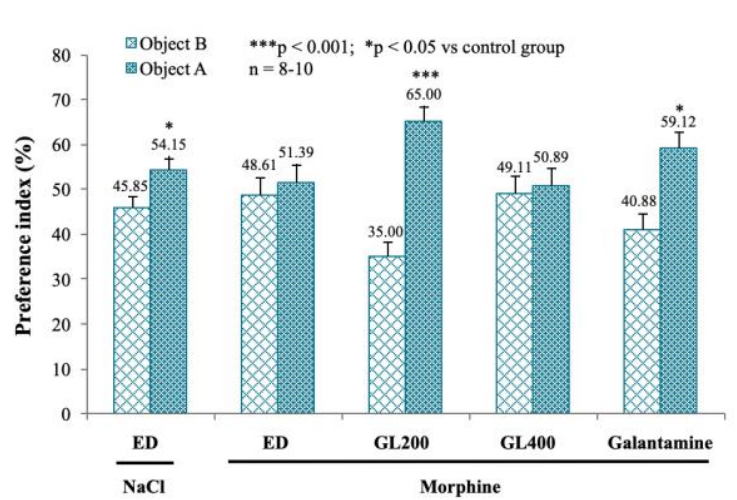

Figure 2. Preference indexes of object A and object B of experimental groups in a training phase

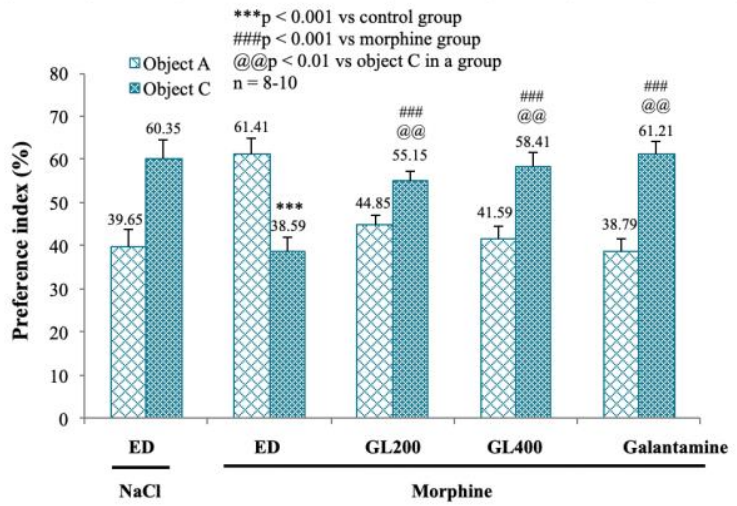

Figure 3. Preference indexes of object $A$ (familiar) and object $\mathrm{C}$ (novel) of experimental groups in a test phase

\subsubsection{Morris water maze test.}

On the first day of the hidden platform test, no meaningful difference was found among all experimental groups, demonstrating that experimental substances did not affect mice's movement ability, and the initial memory ability among groups was equal. In the following days, the time mice in the control group spent on locating the hidden platform gradually decreased to roughly 12 seconds on the fourth day, while the mice who received morphine remained higher figures ( $p<0.05$ ). The groups of mice administered GL at doses of $200 \mathrm{mg} / \mathrm{kg}$ and $400 \mathrm{mg} / \mathrm{kg}$, and galantamine $10 \mathrm{mg} / \mathrm{kg}$ also recorded improvements in the time locating the hidden platform in the fourth day, from 15 to 20 seconds. Meanwhile, GL proved its effects on improving morphine-induced long-term memory impairment. No significant difference was observed in the treatment effectiveness of GL compared to galantamine (Table 2). In the probe test, the number of times the mice who received morphine swam across the hidden platform was lower than that of the control group $(p<0.05)$. Besides, the number of times the mice administered GL at doses of 200 and $400 \mathrm{mg} / \mathrm{kg}$ crossing the hidden platform was significantly greater than results in the morphine group $(p<0.05)$. In addition, no significant difference was recorded between GL groups and galantamine group ( $p>0.05$ ) (Figure 4). In 3 days of action memory test, the amount of time spent on locating the mice's hidden platform treated with either morphine, GL, or galantamine was significantly higher than that of the control group ( $p<0.05)$. Such value in the mice groups treated with either GL $400 \mathrm{mg} / \mathrm{kg}$ or galantamine is greater, significant shortening compared to the mice treated with morphine $(p<0.05)$. However, no significant difference was observed between the mice treated with GL $200 \mathrm{mg} / \mathrm{kg}$ and the mice treated with morphine $(p>0.05)$ (Figure 5).

Table 2. The amount of time the mice spent on locating hidden platforms.

\begin{tabular}{l|c|c|c|c}
\multirow{2}{*}{ Group } & \multicolumn{3}{|c}{ Escape latency (second) in hidden platform test - training phase } \\
\cline { 2 - 5 } & Day 1 & Day 2 & Day 3 & Day 4 \\
\hline $\mathrm{NaCl} 0.9 \%(\mathrm{n}=8)$ & $31.52 \pm 3.91$ & $18.20 \pm 3.54$ & $13.45 \pm 0.6$ & $11.60 \pm 2.03$ \\
\hline Morphine $(\mathrm{n}=10)$ & $36.64 \pm 3.39$ & $30.20 \pm 2.54^{*}$ & $29.20 \pm 3.8^{*}$ & $26.50 \pm 2.49^{*}$ \\
\hline GL200 + Morphine $(\mathrm{n}=10)$ & $32.98 \pm 4.94$ & $24.86 \pm 4.45$ & $21.00 \pm 4.05$ & $19.23 \pm 2.94^{*}, \#$ \\
\hline GL400 + Morphine ( $=10)$ & $32.53 \pm 3.98$ & $23.00 \pm 3.5$ & $18.37 \pm 2.08^{*}, \#$ & $18.20 \pm 1.53^{*}, \#$ \\
\hline Galantamine + Morphine $(\mathrm{n}=10)$ & $32.14 \pm 3.09$ & $20.40 \pm 3.3^{\#}$ & $17.37 \pm 1.21^{*}, \#$ & $15.48 \pm 2.84^{\#}$
\end{tabular}

The Y maze test and the novel object recognition test aim to assess short-term spatial memory and visual memory based on mice's exploring instinct, respectively. In comparison, the Morris water maze test aims to assess the long-term memory of mice. Learning ability and spatial reference memory are assessed by the amount of time locating the hidden platform $[25$, 
30]. The results illustrated that GL extract at doses of $200 \mathrm{mg} / \mathrm{kg}$ and $400 \mathrm{mg} / \mathrm{kg}$ improved morphine-induced short-term spatial memory impairment and entirely recovered short-term visual memory (object exploration). Our study's obtained results absolutely agreed with previous studies on GL's capability of improving learning memory, promising therapeutic potentiality of GL against Alzheimer's disease progression [21, 31-35].

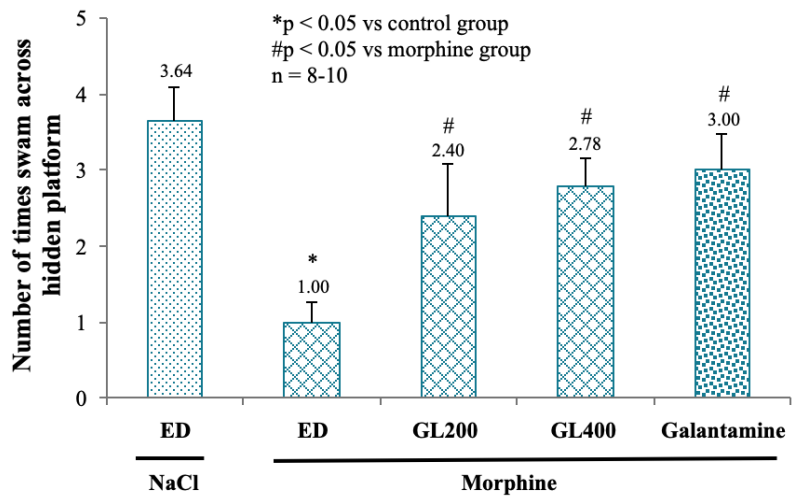

Figure 4. The number of times mice swam across hidden platform in probe test

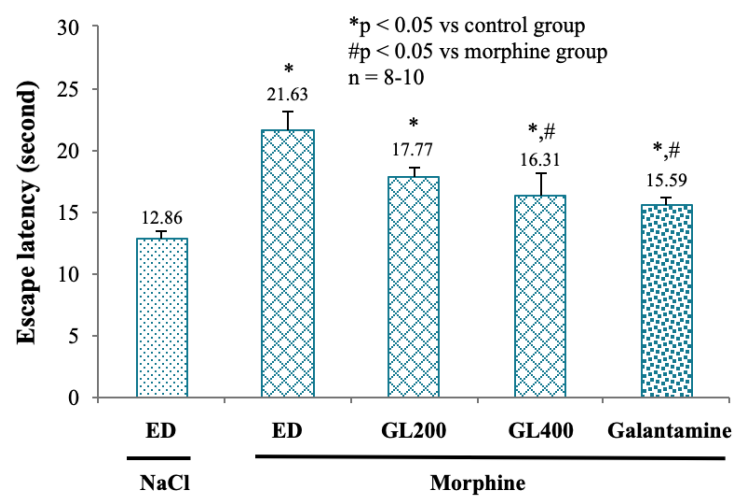

Figure 5. Escape latency of experimental groups in action memory test.

\section{Conclusions}

GL at doses of $200 \mathrm{mg} / \mathrm{kg}$ and $400 \mathrm{mg} / \mathrm{kg}$ administered 7 times for 14 days presented an improvement of morphine addiction, short-term spatial memory, visual memory, and longterm memory impairment caused by morphine. Our results open a further study on bioactive compounds involved in GL.

\section{Funding}

This research received no external funding.

\section{Acknowledgments}

This research has no acknowledgment.

\section{Conflicts of Interest}

The authors declare no conflict of interest.

\section{References}

1. López-Gambero, A.J.; Rodríguez de Fonseca, F.; Suárez, J. Energy sensors in drug addiction: A potential therapeutic target. Addiction Biology 2021, 26, 1-24, https://doi.org/10.1111/adb.12936.

2. Waly, G. The world drug report 2020. Booklet 2 Drug use and health consequences. Office on Drugs and Crime, United Nations, 2020, 10-15.

3. Eidson, L.N.; Murphy, A.Z. Inflammatory mediators of opioid tolerance: implications for dependency and addiction. Peptides 2019, 115, 51-58, https://doi.org/10.1016/j.peptides.2019.01.003.

4. Zeng, X.S.; Geng, W.S.; Wang, Z.Q.; Jia, J.J. Morphine addiction and oxidative stress: the potential effects of thioredoxin-1. Frontiers in Pharmacology 2020, 11, 1-6, https://doi.org/10.3389/fphar.2020.00082.

5. Yang, H.; Sun, J.; Chen, H.; Wang, F.; Li, Y.; Wang, H.; Qu, T. Mesenchymal stem cells from bone marrow attenuated the chronic morphine-induced cAMP accumulation in vitro. Neuroscience Letters 2019, 698, 7680, https://doi.org/10.1016/j.neulet.2018.12.046.

6. Izquierdo, I.; Dias, R.D.; Souza, D.O.; Carrasco, M.A.; Elisabetsky, E.; Perry, M.L. The role of opioid peptides in memory and learning. Behavioural Brain Research 1980, 1, 451-468, https://doi.org/10.1016/0166-4328(80)90001-7. 
7. Houj, M.; Bisaga, A.; Popik, P. Conditioned rewarding effects of morphine and methadone in mice preexposed to cocaine. Pharmacological Reports 2013, 65, 1176-1184, https://doi.org/10.1016/S17341140(13)71475-0.

8. Huston, J.P.; Silva, M.A.D.S.; Topic, B.; Müller, C.P. What's conditioned in conditioned place preference? Trends in Pharmacological Sciences 2013, 34, 162-166, https://doi.org/10.1016/j.tips.2013.01.004.

9. Farkhondeh, T.; Forouzanfar, F.; Roshanravan, B.; Samarghandian, S. Curcumin effect on nonamyloidogenic pathway for preventing Alzheimer's disease. Biointerface Research in Applied Chemistry 2020, 9, 4085-4089, https://doi.org/10.33263/BRIAC94.085089.

10. Farkhondeh, T.; Azimi-Nezhad, M.; Samini, F.; Pourbagher-Shahri, A.M.; Samarghandian, S. Neuroprotective effect of Alpinia galanga against middle cerebral artery occlusion-induced ischemia in rat. Biointerface Research in Applied Chemistry 2020, 10, 6273-6281, https://doi.org/10.33263/BRIAC105.62736281.

11. Cain, S.M.; Ahn, S.; Garcia, E.; Zhang, Y.; Waheed, Z.; Tyson, J.R.; Yang, Y.; Van Sung, T.; Phillips, A.G.; Snutch, T.P. Heantos-4, a natural plant extract used in the treatment of drug addiction, modulates T-type calcium channels and thalamocortical burst-firing. Molecular Brain 2016, 9, 1-12, https://doi.org/10.1186/s13041-016-0274-7.

12. Pari, N.; Parichehreh, Y.; Alireza, R.; Naser, A. The role of Smyrnium cordifolium Boiss extract and curzerene on withdrawal syndrome in mice. Cellular and Molecular Biology 2019, 65, 77-83, http://dx.doi.org/10.14715/cmb/2019.65.7.14.

13. Singh, P.; Sharma, A.; Bordoloi, M.; Nandi, S.P. Molecular identification of endophytic fungi isolated from medicinal plant. Biointerface Research in Applied Chemistry 2020, 10, 6436-6443, https://doi.org/10.33263/BRIAC105.64366443.

14. Ashrafi, H.; Azadi, A.; Mohammadi-Samani, S.; Hamidi, M. New candidate delivery system for Alzheimer's disease: deferoxamine nanogels. Biointerface Research in Applied Chemistry 2020, 10, 7106-7119, https://doi.org/10.33263/BRIAC106.71067119.

15. Ahmad, M.F. Ganoderma lucidum: A rational pharmacological approach to surmount cancer. Journal of Ethnopharmacology 2020, 260, 1-12, https://doi.org/10.1016/j.jep.2020.113047.

16. Shaher, F.; Qiu, H.; Wang, S.; Hu, Y.; Wang, W.; Zhang, Y.; Wei, Y.; Al-Ward, H.; Abdulghani, M.A.M.; Alenezi, S.K.; Baldi, S.; Zhou, S. Associated targets of the antioxidant cardioprotection of Ganoderma lucidum in diabetic cardiomyopathy by using open targets platform: a systematic review. BioMed Research International 2020, 2020, https://doi.org/10.1155/2020/7136075.

17. Bhat, Z.A.; Abdul H.W.; Mohd Y.B.; Abdul R.M. Major bioactive triterpenoids from Ganoderma species and their therapeutic activity: a review. Asian Journal of Pharmaceutical and Clinical Research 2019, 12, 22-30, https://doi.org/10.22159/ajpcr.2019.v12i4.32124.

18. Aljadaan, S.A.N.; Elias, R.S.; Al-Anssari, R. A. Investigation of the antioxidant and antibacterial activity of novel quercetin derivatives. Biointerface Research in Applied Chemistry 2020, 10, 7329-7336, https://doi.org/10.33263/BRIAC106.73297336.

19. Lai, C.S.W.; Yu, M.S.; Yuen, W.H.; So, K.F.; Zee, S.Y.; Chang, R.C.C. Antagonizing $\beta$-amyloid peptide neurotoxicity of the anti-aging fungus Ganoderma lucidum. Brain Research 2008, 1190, 215-224, https://doi.org/10.1016/j.brainres.2007.10.103.

20. Zhou, Y.; Qu, Z.Q.; Zeng, Y.S.; Lin, Y.K.; Li, Y.; Chung, P.; Wong, R.; Hägg, U. Neuroprotective effect of preadministration with Ganoderma lucidum spore on rat hippocampus. Experimental and Toxicologic Pathology 2012, 64, 673-680, https://doi.org/10.1016/j.etp.2010.12.011.

21. Garber, J.; Barbee, W.; Bielitzki, J.; Clayton, L.; Donovan, J.; Kohn, D.; Lipman, N.; Locke, P.; Melcher, J.; Quimby, F.; Turner, P.; Wood, G.; Wurbel, H. Guide for the care and use of laboratory animals. 8th ed.; Washington: The National Academies Press, 2011.

22. Bardo, M.T.; Bevins, R.A. Conditioned place preference: What does it add to our preclinical understanding of drug reward? Psychopharmacology 2000, 153, 31-43, https://doi.org/10.1007/s002130000569.

23. Kitanaka, J.; Kitanaka, N.; Scott Hall, F.; Fujii, M.; Goto, A.; Kanda, Y.; Koizumi, A.; Kuroiwa, H.; Mibayashi, S.; Muranishi, Y.; Otaki, S.; Sumikawa, M.; Tanaka, K.I.; Nishiyama, N.; Uhl, G.R.; Takemura, M. Memory impairment and reduced exploratory behavior in mice after administration of systemic morphine. Journal of Experimental Neuroscience 2015, 9, 27-35, https://doi.org/10.4137/JEN.S25057.

24. Bertaina-Anglade, V.; Enjuanes, E.; Morillon, D.; Drieu la Rochelle, C. The object recognition task in rats and mice: a simple and rapid model in safety pharmacology to detect amnesic properties of a new chemical entity. Journal of Pharmacological and Toxicological Methods 2006, 54, 99-105, https://doi.org/10.1016/j.vascn.2006.04.001.

25. D'Hooge, R.; De Deyn, P.P. Applications of the Morris water maze in the study of learning and memory. Brain Research Reviews 2001, 36, 60-90, https://doi.org/10.1016/S0165-0173(01)00067-4.

26. Zhang, T.; Yanagida, J.; Kamii, H.; Wada, S.; Domoto, M.; Sasase, H.; Deyama, S.; Takarada, T.; Hinoi, E.; Sakimura, K.; Yamanaka, A.; Maejima, T.; Mieda, M.; Sakurai, T.; Nishitani, N.; Nagayasu, K.; Kaneko, S.; Minami, M.; Kaneda, K. Glutamatergic neurons in the medial prefrontal cortex mediate the formation and retrieval of cocaine-associated memories in mice. Addiction Biology 2020, 25, 1-11, https://doi.org/10.1111/adb.12723. 
27. Shirazy, M.; RayatSanati, K.; Jamali, S.; Motamedi, F.; Haghparast, A. Role of orexinergic receptors in the dentate gyrus of the hippocampus in the acquisition and expression of morphine-induced conditioned place preference in rats. Behavioural Brain Research, 2020, 379, https://doi.org/10.1016/j.bbr.2019.112349.

28. Rosa, H.Z.; Barcelos, R.C.S.; Segat, H.J.; Roversi, K.; Dias, V.T.; Milanesi, L.H.; Burger, M.E. Physical exercise modifies behavioral and molecular parameters related to opioid addiction regardless of training time. $\quad$ European $\quad$ Neuropsychopharmacology $\quad \mathbf{2 0 2 0}, \quad 32, \quad$ 25-35, https://doi.org/10.1016/j.euroneuro.2019.12.111.

29. Pu, L.; Bao, G.; Xu, N.; Ma, L.; Pei, G. Hippocampal long-term potentiation is reduced by chronic opiate treatment and can be restored by re-exposure to opiates. The Journal of Neuroscience 2002, 22, 1914-1921, http://dx.doi.org/10.1523/JNEUROSCI.22-05-01914.2002.

30. Buccafusco, J.J. Methods of Behavior Analysis in Neuroscience. 2nd ed.; Taylor and Francis, 2009; pp. 5976.

31. Chu, Q.P.; Wang, L.E.; Cui, X.Y.; Fu, H.Z.; Lin, Z.B.; Lin, S.Q.; Zhang, Y.H. Extract of Ganoderma lucidum potentiates pentobarbital-induced sleep via a GABAergic mechanism. Pharmacology Biochemistry and Behavior 2007, 86, 693-698, https://doi.org/10.1016/j.pbb.2007.02.015.

32. Chan, P.; Zhang, R.; Xu, S.; Cai, Y.; Zhou, M.; Zuo, X. Ganoderma lucidum protects dopaminergic neuron degeneration through inhibition of microglial activation. Evidence-Based Complementary and Alternative Medicine 2011, 2011, 1-9, https://doi.org/10.1093/ecam/nep075.

33. Khatian, N.; Aslam, M. Effect of Ganoderma lucidum on memory and learning in mice. Clinical Phytoscience 2019, 5, 1-8, https://doi.org/10.1186/s40816-019-0101-7.

34. Rahman, MA.; Hossain, S.; Abdullah, N.; Aminudin, N. Lingzhi or reishi medicinal mushroom, Ganoderma lucidum (Agaricomycetes), ameliorates nonspatial learning and memory deficits in rats with hypercholesterolemia and Alzheimer's disease. International Journal of Medicinal Mushrooms 2020, 22, 1067-1078, https://doi.org/10.1615/IntJMedMushrooms.2020036354.

35. Zhao, C.; Zhang, C.; Xing, Z.; Ahmad, Z.; Li, J.S.; Chang, M.W. Pharmacological effects of natural Ganoderma and its extracts on neurological diseases: A comprehensive review. International Journal of Biological Macromolecules 2019, 121, 1160-1178, https://doi.org/10.1016/j.ijbiomac.2018.10.076. 